\title{
Distinction of cardiometabolic profiles among people $\geq 75$ years with type 2 diabetes: a latent profile analysis
}

\author{
Antoine CHRISTIAENS ${ }^{1,2,3^{*}}$ (D), Michel P. HERMANS ${ }^{4,5}$, Benoit BOLAND ${ }^{3,6}$ and Séverine HENRARD ${ }^{2,3}$
}

\begin{abstract}
Background: Older patients with type 2 diabetes mellitus represent a heterogeneous group in terms of metabolic profile. It makes glucose-lowering-therapy (GLT) complex to manage, as it needs to be individualised according to the patient profile. This study aimed to identify and characterize subgroups existing among older patients with diabetes.

Methods: Retrospective observational cohort study of outpatients followed in a Belgian diabetes clinic. Included participants were all aged $\geq 75$ years, diagnosed with type 2 diabetes, Caucasian, and had a Homeostasis Model Assessment (HOMA2). A latent profile analysis was conducted to classify patients using the age at diabetes diagnosis and HOMA2 variables, i.e. insulin sensitivity (HOMA2\%-S), beta-cell-function (HOMA2\%- $\beta$ ), and the product between both (HOMA2\%- $\beta \times S$; as a measure of residual beta-cell function). GLT was expressed in defined daily dose (DDD).
\end{abstract}

Results: In total, 147 patients were included (median age: 80 years; 37.4\% women; median age at diabetes diagnostic: 62 years). The resulting model classified patients into 6 distinct cardiometabolic profiles. Patients in profiles 1 and 2 had an older age at diabetes diagnosis (median: 68 years) and a lesser decrease in HOMA2\%-S, as compared to other profiles. They also presented with the highest HOMA2\%- $\times$ XS values. Patients in profiles 3,4 and 5 had a moderate decrease in HOMA2\%- $\beta \times S$. Patients in profile 6 had the largest decrease in HOMA2\%- $\beta$ and HOMA2\%- $\beta \times S$. This classification was associated with significant differences in terms of HbA1c values and GLT total DDD between profiles. Thus, patients in profiles 1 and 2 presented with the lowest HbA1c values (median: 6.5\%) though they received the lightest GLT (median GLT DDD: 0.75). Patients in profiles 3 to 5 presented with intermediate values of HbA1c (median: 7.3\% and GLT DDD (median: 1.31). Finally, patients in profile 6 had the highest HbA1c values (median: 8.4\%) despite receiving the highest GLT DDD (median: 2.28). Other metabolic differences were found between profiles.

Conclusions: This study identified 6 groups among patients $\geq 75$ years with type 2 diabetes by latent profile analysis, based on age at diabetes diagnosis, insulin sensitivity, absolute and residual $\beta$-cell function. Intensity and choice of GLT should be adapted on this basis in addition to other existing recommendations for treatment individualisation.

Keywords: Cardiometabolic profile, Homeostasis model assessment, Older patients, Type 2 diabetes, Type 2 diabetes classification, Type 2 diabetes management

\footnotetext{
* Correspondence: antoine.christiaens@uclouvain.be

${ }^{1}$ Fonds national de la recherche scientifique - F.R.S-FNRS, Brussels, Belgium

${ }^{2}$ Clinical Pharmacy Research Group, Louvain Drug Research Institute (LDRI),

UCLouvain, Brussels, Belgium

Full list of author information is available at the end of the article
}

(c) The Author(s). 2019 Open Access This article is distributed under the terms of the Creative Commons Attribution 4.0 International License (http://creativecommons.org/licenses/by/4.0/), which permits unrestricted use, distribution, and reproduction in any medium, provided you give appropriate credit to the original author(s) and the source, provide a link to the Creative Commons license, and indicate if changes were made. The Creative Commons Public Domain Dedication waiver (http://creativecommons.org/publicdomain/zero/1.0/) applies to the data made available in this article, unless otherwise stated. 


\section{Background}

Type 2 diabetes is one of the most prevalent chronic diseases worldwide, especially among older people aged $\geq 75$ years, in whom prevalence reached $20 \%$ in 2017, and is poised to increase over the coming decades [1]. In Europe, the cost per patient per year with diabetes mellitus was estimated at US Dollar 3,100 in 2017. Moreover, diabetes was responsible for $10 \%$ of total health care expenditure in 2010 [2]. Diabetes in older patients has therefore a major impact on healthcare systems.

Current classification of diabetes mellitus considers 4 different categories: type 1 diabetes, type 2 diabetes, gestational diabetes and specific rare types of diabetes [3]. In older age, type 2 diabetes is reported to represent $85-90 \%$ of all-cause diabetes, ahead of type 1 diabetes, which includes latent autoimmune diabetes in adults $[4,5]$.

Type 2 diabetes induces specific acute or chronic complications (e.g. microvascular complications from chronic hyperglycaemia) and increases the incident risk of macrovascular complications from various cardiometabolic abnormalities promoting the occurrence of atherosclerosis [6]. These vascular complications promote and intensify the development of several geriatric syndromes in older patients, such as falls, polymedication, cognitive disorders or sensorial disorders $[6,7]$. The aim of glucose lowering therapy (GLT) in these patients is to control hyperglycaemia and its associated morbidity and mortality. Nevertheless, in older patients with type 2 diabetes, GLT should be adapted according to patient's characteristics in order to be intense enough to avoid microvascular complications but light enough to prevent potential side-effects of GLT, mainly hypoglycaemia, as it also increases morbidity and mortality [7]. These considerations offer only a narrow frame to perform a safe and effective GLT management in patients aged 75 years or more with type 2 diabetes. Several recent guidelines provide recommendations about GLT management in older patients with diabetes, in terms of hyperglycaemia, risk factors and complications $[8,9]$. These guidelines and other reports all insist on treatments' individualisation in order to give tailored medication for each patient [8, 10-15]. At present, factors currently considered in this treatment individualisation are related to the type of diabetes [3], but also to prevalent comorbidities, geriatric syndromes, nutrition issues, physical activity, age-specific aspects of pharmacotherapy, ethnic disparities and estimated life expectancy $[8,11]$.

Indeed, type 2 diabetes is a complex condition with marked heterogeneity in pathophysiological mechanisms leading to hyperglycaemia and cardiometabolic comorbidities between patients. Ageing process enhances this heterogeneity, adding other conditions, such as nutritional deficits, sarcopenia, additional stresses on pancreatic betacells and micro-inflammation [16-18].
Yet, current guidelines for older patients do not suggest taking into account characteristics related to the pathophysiology of diabetes or severity of residual betacell function (BCF) loss. Therefore, it is of interest to consider these factors in GLT individualisation in order to improve the quality, efficacy and safety of GLT management in older patients.

Therefore, the aim of the present study was to assess the heterogeneity of cardiometabolic features in patients aged 75 years or more with type 2 diabetes and to classify them into relevant cardiometabolic profiles using mixture models as Latent Profile Analysis (LPA).

\section{Methods}

\section{Study design and patient selection}

A retrospective cohort study of outpatients followed by the same investigator (MPH) between 2000 and 2017 and attending a Belgian university diabetes clinic was conducted. Among the 266 Caucasian patients followed in the diabetes clinic and aged $\geq 75$ years at the last two visits to the endocrinologist, 147 participants had a Homeostasis Model Assessment (HOMA2) after the diagnosis of their type 2 diabetes. All 147 participants were GAD-antibodies-negative. Type 2 diabetes was defined according to the Expert Committee on the Diagnosis and Classification of Diabetes Mellitus [3].

This study was approved by the local Ethics Committee (Commission d'Ethique Hospitalo-Facultaire, Cliniques universitaires Saint-Luc, Brussels, Belgium; ref. B403/2017/16NOV/521).

\section{Data collection}

A first part of the data was collected at the time of the HOMA2 assessment. Data included anthropometric (weight, body mass index and fat mass proportion), biochemical (HbA1c) and ongoing GLT (drug molecules and doses).

Body mass index (BMI; $\left.\mathrm{kg} / \mathrm{m}^{2}\right)$ was calculated as [Weight $\left.(\mathrm{kg}) \times \operatorname{Height}(\mathrm{m})^{-2}\right]$. Body fat mass (\%) was measured using a BodyFat Analyser (Omron BF 500; Omron Healthcare Europe B.V., Hoofddorp, The Netherlands). HbA1c was expressed in NGSP nomenclature (\%) and was converted to IFCC nomenclature $(\mathrm{mmol} / \mathrm{mol})$ using the NGSP convertor (www.ngsp.org/convert1.asp).

Insulin sensitivity and beta-cell function were assessed using the computer-based homeostasis model assessment (HOMA2, http://www.dtu.ox.ac.uk) [19]. HOMA2 parameters were calculated from triplicates of fasting glucose and insulin level, sampled after a sufficient period of GLT washout (i.e. between 1 to 5 days, according to the molecules involved). Values of insulin secretion (HOMA2\%- $\beta$ (\%); normal $100 \%)$ were plotted as a function of insulin sensitivity (HOMA2\%-S (\%); normal $100 \%$ ), defining a hyperbolic product area (HOMA2\%- 
$\beta x S\left(\%^{2}\right)$; normal $\left.100 \%\right)$. This product described the interaction between insulin sensitivity and insulin secretion, or more precisely, the true latent beta-cell function (BCF) indexed by insulin sensitivity. It approximates the magnitude of glucose homeostasis deficit and the required GLT intensity [20].

GLT data corresponded to the treatment taken one week before the HOMA2 realization. Drugs were transcribed into Anatomical Therapeutic Chemical (ATC) codes and grouped by GLT classes (A10A-Insulin, A10BAbiguanides, A10BB-sulfonylureas, A10BF-alpha-glucosidase-inhibitors, A10BG-thiazolidinediones, A10BH-DPP4inhibitors, A10BJ-GLP1-receptor agonists, A10BX-other). Sulfonylureas and repaglinide were considered as "Oral hypoglycaemic agents (OHA)" and insulin and OHA were considered as "Hypoglycaemic agents (HA)". Patients with no GLT were considered as "Lifestyle changes only". Treatment doses were collected and converted into Defined Daily Dose (DDD), according to the ATC/DDD Index 2018 [21]. For each patient, a sum of the GLT drugs doses, expressed in DDD, was computed and described hereafter as "GLT's total doses".

The second part of the data was collected at the time of the last consultation at the diabetes clinic, at which all patients were $\geq 75$ years, and included sociodemographic (age, sex) and diabetes-related data (age at diabetes diagnosis, comorbidities, vascular complications). Micro-angiopathic complications were defined as: neuropathy (clinical examination of knee and ankle reflexes; Semmes-Weinstein monofilament test, confirmed by lower-limbs electromyography) and diabetic retinopathy (based on retinal examination by an experienced ophthalmologist and/or fluorescein angiography). Diabetic nephropathy was not taken into account in this study because of its high prevalence in older age and its multiple aetiologies that cannot be attributed de facto to chronic hyperglycaemia.

Macro-angiopathic complications included coronary artery disease (CAD: myocardial infarction, angioplasty, stenting, revascularization surgery and/or significant coronary stenosis confirmed by angiography), cerebrovascular disease (CVD) or peripheral artery disease (PAD). CVD was defined according to UK Prospective Diabetes Study criteria: any neurological deficit $\geq 1$ month, without distinction between ischemic, embolic and haemorrhagic events [22]. PAD was diagnosed from medical history of lower-limb claudication; clinical or imaging evidence for ischemic diabetic foot; history of angioplasty, stenting, revascularization surgery; and/or lower-limb artery stenosis at Doppler ultrasonography or angiography.

\section{Statistical analysis}

Continuous data were expressed as medians (P25, P75). Categorical data were expressed as number of people and percentages. Continuous variables were compared between 2 groups using Mann Whitney test, and between $\geq 3$ groups using Kruskal-Wallis test. Categorical variables were compared between groups using Pearson's $X^{2}$ test, Pearson's $X^{2}$ test with Yates correction, Fisher's exact test or Fisher Freeman Halton's test, according to the conditions of validity of each test.

In order to identify profiles of patients with type 2 diabetes a latent profile analysis (LPA) was performed using the following continuous discriminant variables (indicators): insulin sensitivity (HOMA2\%-S), BCF (HOMA2\%$\beta)$, hyperbolic product $\beta \times S(H O M A 2 \%-\beta \times S)$ and age at diabetes diagnosis. Models with 2 to 7 profiles were ran. Evaluative information was used to select the best model, e.g. the model with the lowest Akaike information criteria, Bayesian Information Criterion (BIC) and Log Likelihood (LL) [23]. In addition, the likelihood ratio test was used to compare a model with $\mathrm{k}-1$ profiles with a model with $\mathrm{k}$ profiles. Finally, posterior probabilities, i.e. the probability of each patient of belonging to each profile, were computed for the final selected model. An average posterior probability per group $\geq 0.70$ was used to consider whether profiles were sufficiently separated from each other.

Statistical analyses were performed using IBM SPSS Statistics $25^{\circ}$ software or $\mathrm{R}$ software $(\mathrm{R} \times 64$ version 3.4.1). A $p$-value $<0.05$ was considered statistically significant.

\section{Results}

\section{Patients' characteristics}

The 147 older patients ( $\geq 75$ years of age; $37 \%$ women) had a median age of 62.0 years at diabetes diagnosis and a median duration of diabetes of 19.0 years at the last visit at the diabetes clinic (Table 1, left column). According to HOMA2-modeling, median insulin sensitivity was $47.4 \%$ and median BCF was $49.3 \%$. Median hyperbolic product of insulin sensitivity and beta-cell function $\beta x S$ ) was $25.0 \%$ and median $\mathrm{HbA} 1 \mathrm{c}$ was $7.1 \%(54 \mathrm{mmol} / \mathrm{mol})$ at the time of the HOMA2 testing.

\section{Profiles of older patients with type 2 diabetes}

Using latent profile analysis, a 6-profile model was the best-fitting model based on evaluative information (see Additional file 1). In addition, in this model, the average probability of each patient to belong to each group ranged from 0.904 in profile 4 to 0.977 in profile 2, showing good separation between profiles (see Additional file 2).

\section{Profiles' characteristics collected at the HOMA2 assessment}

HOMA2 was realized at similar median ages in the 6 profiles, between 71.0 and 73.5 years $(p=0.714)$ (Table 1). All 
Table 1 Patients' characteristics by cardiometabolic profiles created in latent profile analysis $(N=147)$

\begin{tabular}{|c|c|c|c|c|c|c|c|c|}
\hline Variables & $\begin{array}{l}\text { Total }(N=147) \\
\text { Median }[\mathrm{P} 25 ; \\
\text { P75] } \\
\text { or } \mathrm{n}(\%)\end{array}$ & $\begin{array}{l}\text { Profile } 1 \text { ( } n= \\
16) \\
\text { Median [P25; } \\
\text { P75] } \\
\text { or } n(\%)\end{array}$ & $\begin{array}{l}\text { Profile } 2 \text { ( } n= \\
14) \\
\text { Median [P25; } \\
\text { P75] } \\
\text { or } n(\%)\end{array}$ & $\begin{array}{l}\text { Profile } 3 \text { ( } n= \\
23) \\
\text { Median [P25; } \\
\text { P75] } \\
\text { or } \mathrm{n}(\%)\end{array}$ & $\begin{array}{l}\text { Profile } 4 \text { ( } n= \\
29) \\
\text { Median [P25; } \\
\text { P75] } \\
\text { or } n(\%)\end{array}$ & $\begin{array}{l}\text { Profile } 5(n= \\
28) \\
\text { Median [P25; } \\
\text { P75] } \\
\text { or } n(\%)\end{array}$ & $\begin{array}{l}\text { Profile } 6(\mathrm{n}= \\
37) \\
\text { Median [P25; } \\
\text { P75] } \\
\text { or } n(\%)\end{array}$ & $\begin{array}{l}P- \\
\text { value }\end{array}$ \\
\hline \multicolumn{9}{|c|}{ Characteristics at the time of the last consultation } \\
\hline Age, in years & $\begin{array}{l}80.0[77.0 ; \\
83.0]\end{array}$ & $\begin{array}{l}80.5[76.0 ; \\
82.8]\end{array}$ & $\begin{array}{l}80.0[78.0 ; \\
84.0]\end{array}$ & $\begin{array}{l}77.0[76.0 ; \\
81.0]\end{array}$ & $\begin{array}{l}79.0[76.0 ; \\
82.0]\end{array}$ & $\begin{array}{l}80.0[77.0 ; \\
83.8]\end{array}$ & $\begin{array}{l}81.0[77.0 ; \\
84.0]\end{array}$ & 0.545 \\
\hline Women & $55(37.4)$ & $6(37.5)$ & $4(28.6)$ & $12(52.2)$ & $14(48.3)$ & $7(25.0)$ & $12(32.4)$ & 0.278 \\
\hline $\begin{array}{l}\text { Family history of } \\
\text { diabetes* }\end{array}$ & $52(35.4)$ & $4(25.0)$ & $4(30.8)$ & $5(21.7)$ & $11(37.9)$ & $11(39.3)$ & $17(49.6)$ & 0.348 \\
\hline $\begin{array}{l}\text { Diabetes duration, in } \\
\text { years }\end{array}$ & $\begin{array}{l}19.0[12.0 ; \\
27.0]\end{array}$ & $12.0[3.3 ; 14.8]$ & $15.0[9.8 ; 20.3]$ & $12.0[5.0 ; 23.0]$ & $\begin{array}{l}20.0[15.5 ; \\
28.0]\end{array}$ & $\begin{array}{l}23.5[17.3 ; \\
29.0]\end{array}$ & $\begin{array}{l}22.0[14.5 ; \\
27.5]\end{array}$ & $\begin{array}{l}< \\
0.001\end{array}$ \\
\hline \multicolumn{9}{|c|}{ Characteristics at the time of $\mathrm{HOMA2}$} \\
\hline $\begin{array}{l}\text { Age at } \mathrm{HOMA} 2 \text {, in } \\
\text { years }\end{array}$ & $\begin{array}{l}72.0[69.0 ; \\
76.0]\end{array}$ & $\begin{array}{l}73.5[70.3 ; \\
76.5]\end{array}$ & $\begin{array}{l}72.0[70.0 ; \\
73.3]\end{array}$ & $\begin{array}{l}71.0[64.0 ; \\
76.0]\end{array}$ & $\begin{array}{l}71.0[66.0 ; \\
77.0]\end{array}$ & $\begin{array}{l}71.0[68.3 ; \\
74.8]\end{array}$ & $\begin{array}{l}73.0[68.0 ; \\
77.0]\end{array}$ & 0.714 \\
\hline $\mathrm{BMl}$, in $\mathrm{kg} / \mathrm{m}^{2}$ & $\begin{array}{l}28.3[25.7 ; \\
31.2]\end{array}$ & $\begin{array}{l}26.8[24.9 ; \\
29.6]\end{array}$ & $\begin{array}{l}26.2[24.7 ; \\
33.1]\end{array}$ & $\begin{array}{l}28.0[25.8 ; \\
33.3]\end{array}$ & $\begin{array}{l}29.6[26.6 ; \\
34.6]\end{array}$ & $\begin{array}{l}27.9[25.7 ; \\
29.6]\end{array}$ & $\begin{array}{l}28.2[25.5 ; \\
31.7]\end{array}$ & 0.037 \\
\hline BMI $\left[18-25\left[\mathrm{~kg} / \mathrm{m}^{2}\right.\right.$ & $33(22.4)$ & $4(25.0)$ & $5(35.7)$ & $3(13.0)$ & $8(27.6)$ & $9(32.1)$ & $4(10.8)$ & \\
\hline BMI $\left[25-30\left[\mathrm{~kg} / \mathrm{m}^{2}\right.\right.$ & $68(46.3)$ & $10(62.5)$ & $6(42.9)$ & $9(39.1)$ & $8(27.6)$ & $14(50.0)$ & $21(56.8)$ & \\
\hline $\mathrm{BMI} \geq 30 \mathrm{~kg} / \mathrm{m}^{2}$ & $45(30.6)$ & $2(12.5)$ & $3(21.4)$ & $11(47.8)$ & $13(44.8)$ & $4(14.3)$ & $12(32.4)$ & \\
\hline $\mathrm{HbA} 1 \mathrm{ct}$, in \% & $7.1[6.4 ; 8.2]$ & $6.6[6.0 ; 7.9]$ & $5.4[5.2 ; 6.6]$ & $7.0[6.4 ; 7.9]$ & $7.4[7.1 ; 8.0]$ & $6.8[5.8 ; 7.2]$ & $8.4[7.8 ; 9.1]$ & $\begin{array}{l}< \\
0.001\end{array}$ \\
\hline \multicolumn{9}{|c|}{ Indicators used in latent profile analysis } \\
\hline $\begin{array}{l}\text { Age at diagnosis, in } \\
\text { years }\end{array}$ & $\begin{array}{l}62.0[54.0 ; \\
70.0]\end{array}$ & $\begin{array}{l}70.5[63.3 ; \\
74.0]\end{array}$ & $\begin{array}{l}68.0[61.0 ; \\
70.5]\end{array}$ & $\begin{array}{l}64.0[58.0 ; \\
74.0]\end{array}$ & $\begin{array}{l}58.0[54.5 ; \\
62.0]\end{array}$ & $\begin{array}{l}55.5[47.8 ; \\
67.8]\end{array}$ & $\begin{array}{l}61.0[52.0 ; \\
65.0]\end{array}$ & $\begin{array}{l}< \\
0.001 \neq\end{array}$ \\
\hline HOMA2\%-S, in \% & $\begin{array}{l}47.4[32.1 ; \\
73.0]\end{array}$ & $\begin{array}{l}50.5[47.0 ; \\
56.4]\end{array}$ & $\begin{array}{l}84.1[58.2 ; \\
115.8]\end{array}$ & $\begin{array}{l}22.3[15.1 ; \\
31.4]\end{array}$ & $\begin{array}{l}35.2[29.1 ; \\
42.9]\end{array}$ & $\begin{array}{l}86.3[74.1 ; \\
106.9]\end{array}$ & $\begin{array}{l}48.3[34.3 ; \\
40.2]\end{array}$ & $\begin{array}{l}< \\
0.001 \neq\end{array}$ \\
\hline HOMA2\%- $\beta$, in \% & $\begin{array}{l}49.3[32.4 ; \\
72.6]\end{array}$ & $\begin{array}{l}71.6[68.1 ; \\
76.1]\end{array}$ & $\begin{array}{l}66.5[47.6 ; \\
111.1]\end{array}$ & $\begin{array}{l}111.6[95.1 ; \\
135.5]\end{array}$ & $\begin{array}{l}56.5[46.8 ; \\
65.5]\end{array}$ & $\begin{array}{l}39.2[32.0 ; \\
47.9]\end{array}$ & $\begin{array}{l}27.3[21.7 ; \\
34.9]\end{array}$ & $\begin{array}{l}< \\
0.001 \neq\end{array}$ \\
\hline HOMA $2 \%-\beta \times S$, in \% & $\begin{array}{l}25.0[16.0 ; \\
37.0]\end{array}$ & $\begin{array}{l}36.0[33.3 ; \\
40.5]\end{array}$ & $\begin{array}{l}56.0[52.8 ; \\
64.3]\end{array}$ & $\begin{array}{l}28.0[17.0 ; \\
34.0]\end{array}$ & $\begin{array}{l}20.0[17.0 ; \\
24.0]\end{array}$ & $\begin{array}{l}34.5[28.3 ; \\
39.8]\end{array}$ & $13.0[9.0 ; 16.0]$ & $\begin{array}{l}< \\
0.001 \neq\end{array}$ \\
\hline
\end{tabular}

HOMA2\%-S: insulin sensitivity assessed by Homeostasis Model Assessment 2 (HOMA2); HOMA2\%- $\beta$ : beta-cell function assessed by HOMA2; HOMA2\%- $\beta \times S$ : Hyperbolic product between beta-cell function and insulin sensitivity. BMl: body mass index $\left(\mathrm{kg} \cdot \mathrm{m}^{-2}\right){ }^{*} 3$ missing values $(2.0 \%)$. $\dagger 1$ missing value $(0.7 \%)$. $\neq$ Differences were expected as these indicators were included in the LPA to create the 6 profiles

participants' values were plotted on a HOMA2 graph presenting the relationship between $H O M A 2 \%-\beta$ and $H O M A 2 \%-S$ (Fig. 1). Each profile of patients was distinctly delimited in terms of HOMA2\%- $\beta, H O M A 2 \%-S$. $H O M A 2 \%-\beta \times S$ values were different $(p<0.001)$ across the six profiles (Table 1; Fig. 2c).

No significant difference was found in the six profiles in terms of sex ratio $(p=0.278)$.

Patients in profiles $1(n=16 ; 10.9 \%)$ and $2(n=14$; 9.5\%) had an older age at diabetes diagnosis (median: 70.5 years and 68.0 years, respectively) and had a slight decrease in HOMA2\%- $\beta x S$ (median: 36.0 and $56.0 \%$, respectively) (Table 1; Fig. 2c). Patients in profile 2 had a higher insulin sensitivity than patients in profile 1 (Table 1; Fig. 2a). As profile 2 also had preserved beta-secretion (66.5\%), its HOMA2\%- $\beta \times S$ was the highest $(56 \%)$. From profiles $3(n=14)$ to $5(n=29)$, insulin sensitivity increased, and beta-cell function decreased inversely, resulting in a moderate decrease in $H O M A 2 \%-\beta x S$ in all 3 profiles (median: 28.0, 20.0 and $34.5 \%$, respectively; Table 1; Fig. 2c). Profile $6(n=37)$ had the lowest beta-cell function $(27.3 \%)$ and thereby the lowest HOMA2\%- $\beta x S$ (median: 13.0\%) (Table 1; Fig. 2c).

The six profiles were also significantly different in terms of BMI $(p=0.037)$. Profiles 1 and 2 had the lowest median BMI, while profile 3 and 6 had the highest median values. Obesity (i.e. $\mathrm{BMI} \geq 30.0 \mathrm{~kg} / \mathrm{m}^{2}$ ) was less prevalent in profiles $1(12.5 \%), 2(21.4 \%)$ and $5(14.3 \%)$ than in profiles $3(47.8 \%), 4(44.8 \%)$ and $6(32.4 \%)(p=$ 0.028 ). There was no significant difference in fat mass proportion between profiles $(p=0.137)$, nor in abdominal circumference $(p=0.129)$ (Table 1; Fig. 2; Fig. 3). Finally, the median HbA1c value was higher in profile 6 than in profiles $1,2,3$ and $5(p<0.001)$ (Table 1$)$. 


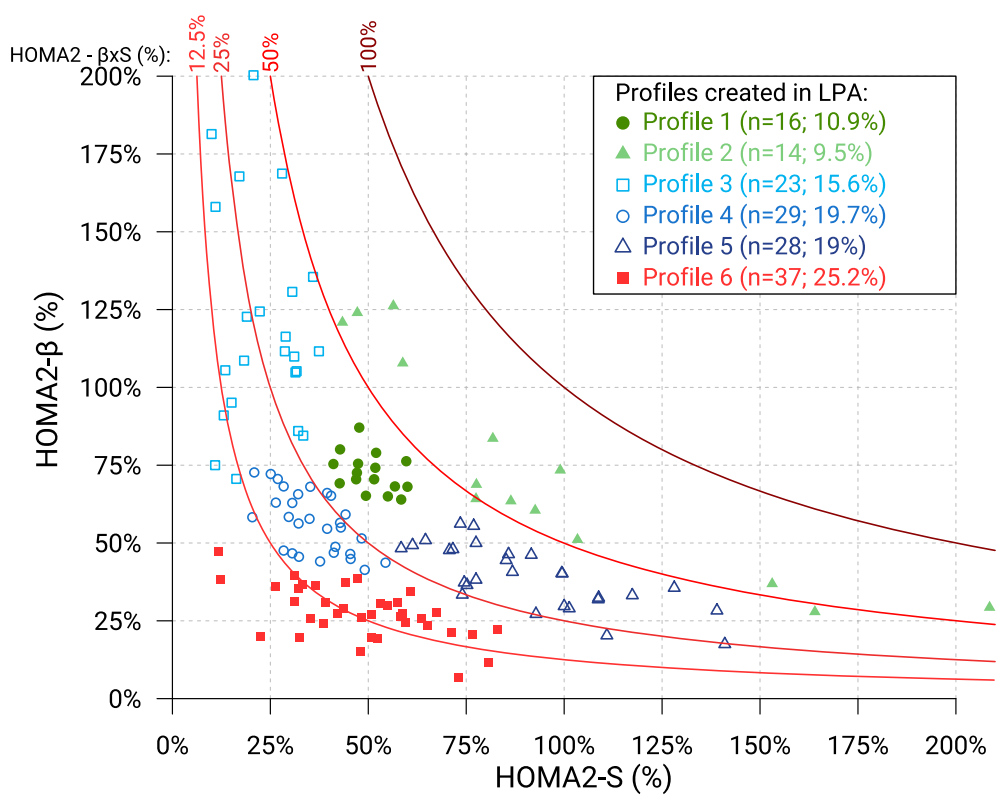

Fig. 1 Distribution of older patients with type 2 diabetes on HOMA2 graph, labeled according to the 6 profiles obtained from the Latent Profile Analysis (LPA). This graph represents insulin sensitivity (HOMA2\%-S) on the $x$-axis and beta-cell function (HOMA2\%- $\beta$ ) on the $y$-axis, both calculated by Homeostasis Model Assessment (HOMA2). The product of HOMA2\%-S and HOMA2\%- $\beta$ is represented on the hyperbolic axis (HOMA2\%- $\beta \times S$ ) at four levels (100, 50, 25, 12.5\%)

Regarding the use of GLT in the six profiles, significant difference was observed in terms of number of glucose-lowering agents $(p<0.001)$ (Table 2). Profiles 1,2 , 3 and 5 had lower number of GLTs than profile 6. Moreover, a higher prevalence of GLT-bi- and -tri-therapy was found in profile 6 . There were no differences in the proportions of patients receiving biguanides, except in profiles 2 and 3 (those with higher residual beta-secretion) (Fig. 1). Insulin was prescribed more frequently in profiles 2, 4 and 6 than in other profiles, as was prescription of hypoglycaemic agents or oral hypoglycaemic agents (Table 2).

In addition to differences within profiles in GLT agents, the median GLT total doses, expressed as daily defined doses (DDD), were different between profiles $(p<0.001)$. Profile 1 and 2 had the lowest median DDD, profiles 3 to 5 had intermediate median DDD and profile 6 had the highest median DDD (Table 2). Profile 6 was significantly different in that respect from profiles 1 , 2,3 and $5(p<0.001)$.

\section{Diabetes complications and comorbidities of each profile at the time of the last consultation}

At the date of the last consultation to the diabetes clinic, profiles 1 and 2 had the lowest prevalence of diabetic retinopathy (13 and $7 \%$, respectively), and profile 6 the highest prevalence $(68.6 \%)(p=0.015$; Table 3; Fig. 3). Profiles 1 and 2 also had the lowest prevalence of diabetic neuropathy and all-cause- microangiopathy (diabetic retinopathy and neuropathy), and profile 6 the highest one, without statistically significant differences (Table 3; Fig. 3).

Differences were also found in terms of all-cause macroangiopathy prevalence $(p=0.017)$. Profile 6 had the highest prevalence of macroangiopathy (75.7\%), unlike profile 1 (25.0\%). Profiles 2 to 5 had intermediate prevalence of macroangiopathy $(42.9,60.9,51.7$ and $50.0 \%$ respectively). Finally, a familial history of type 2 diabetes was less prevalent in profile $3(21.7 \%)$ and profile $1(25.0 \%)$ than in other profiles, in particular profile 6 (48.6\%), but no significant difference was found between profiles $(p=0.348)$. Among the 6 profiles, no significant difference was found in terms of age at the time of last consultation $(p=0.545)$ (Table 1; Fig. 3; Table 3).

\section{Discussion}

The aim of the present study was to classify older patients with type 2 diabetes into profiles using a LPA methodology based on their metabolic features, in order to select more appropriate GLT in terms of their diabetes attributes and metabolic phenotype, and doing so to add another dimension to treatment individualisation [8] based on diabetes characteristics.

The indicators used as discriminant variables input for LPA were selected on the basis of recent literature. First, as suggested in several studies, age at diabetes' diagnosis is a major determinant of metabolic differences. Cardiometabolic profile is usually less severe in patients with an 

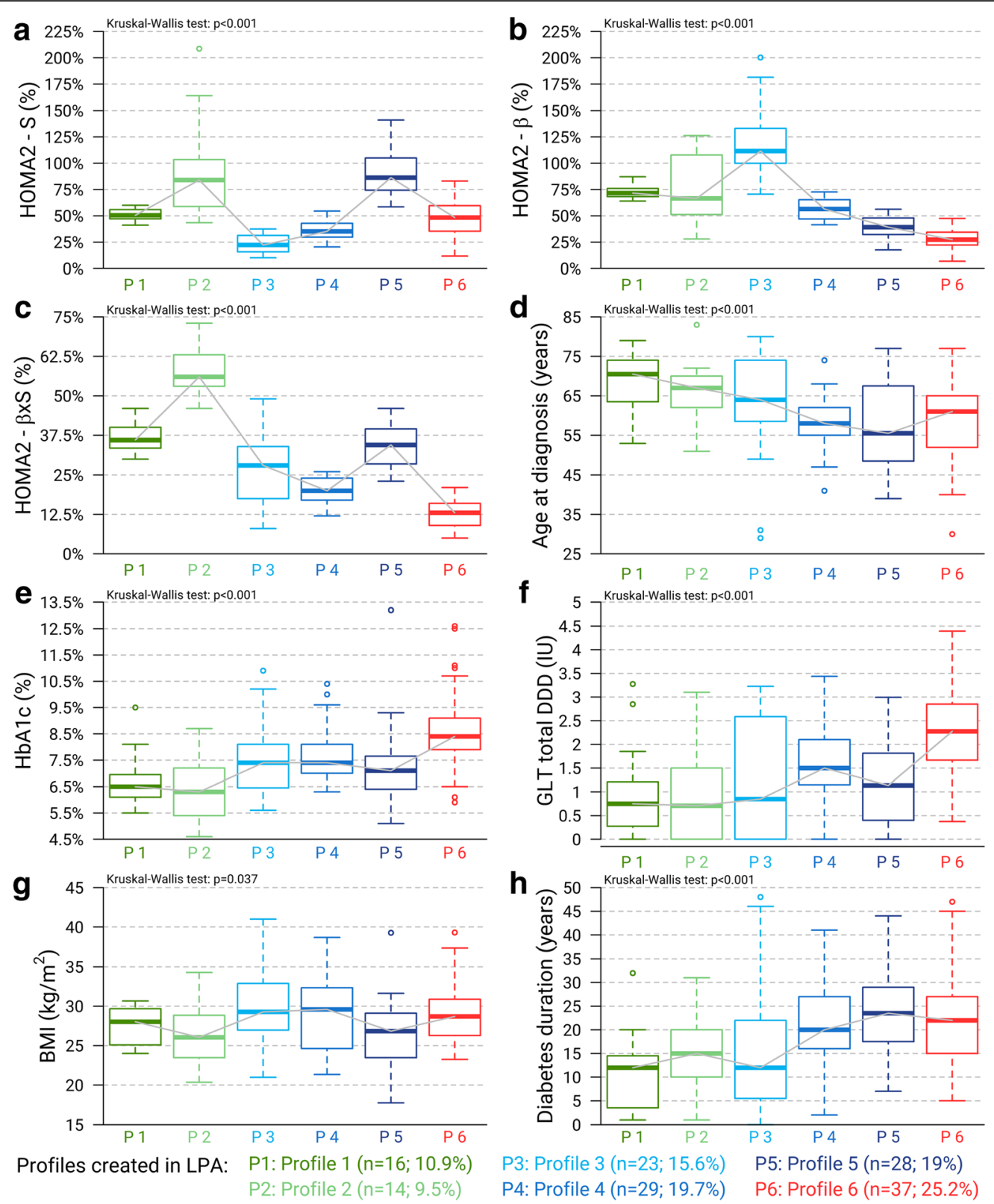

Fig. 2 Distribution of patients' diabetes characteristics according to the 6 profiles created in latent profile analysis. Boxplot of patients' (a) insulin sensitivity (HOMA2\%-S) calculated by Homeostasis Model Assessment (HOMA2), (b) beta-cell function (HOMA2\%- $\beta$ ) calculated by Homeostasis Model Assessment (HOMA2), (c) hyperbolic product of insulin sensitivity and beta-cell function (HOMA2\%- $\beta \times S$ ), (d) Age at diagnosis of type 2 diabetes mellitus, (e) HbA1c collected at the time of HOMA2 assessment, (f) Glucose-lowering therapy (GLT) total dose, used just before the HOMA2 assessment, and expressed in Defined Daily Dose (one unrepresented outlier patient in profile 6 whose GLT total DDD $=6.88$ ), (g) BMI $\left(\mathrm{kg} / \mathrm{m}^{2}\right.$; one unrepresented outlier patient in profile 3 whose $\left.\mathrm{BMI}=58.56 \mathrm{~kg} / \mathrm{m}^{2}\right)$, and $(\mathbf{h})$ duration of diabetes until the last endocrinology consultation, according to the 6 profiles created by the Latent Profile Analysis (LPA). Statistical comparisons between profiles were performed using a Kruskal-Wallis test

older age at diabetes diagnosis than in those who are diagnosed younger. The former have lower HbA1c, fasting plasma glucose, fasting insulin, insulin resistance, triglyceride levels, LDL-cholesterol, BMI, obesity prevalence and family history of diabetes [24-26]. Patients diagnosed with diabetes at an older age also have a lower risk of developing diabetic retinopathy, regardless of known diabetes duration [27]. This suggests that their diabetes might have a lower propensity of generating microvascular complications.

Furthermore, $H O M A 2 \%-S$ and $H O M A 2 \%-\beta$ were used in order to distinct patients in terms of intrinsic glucose homeostasis characteristics, allowing to better select among GLT alternatives. One advantageous feature of 


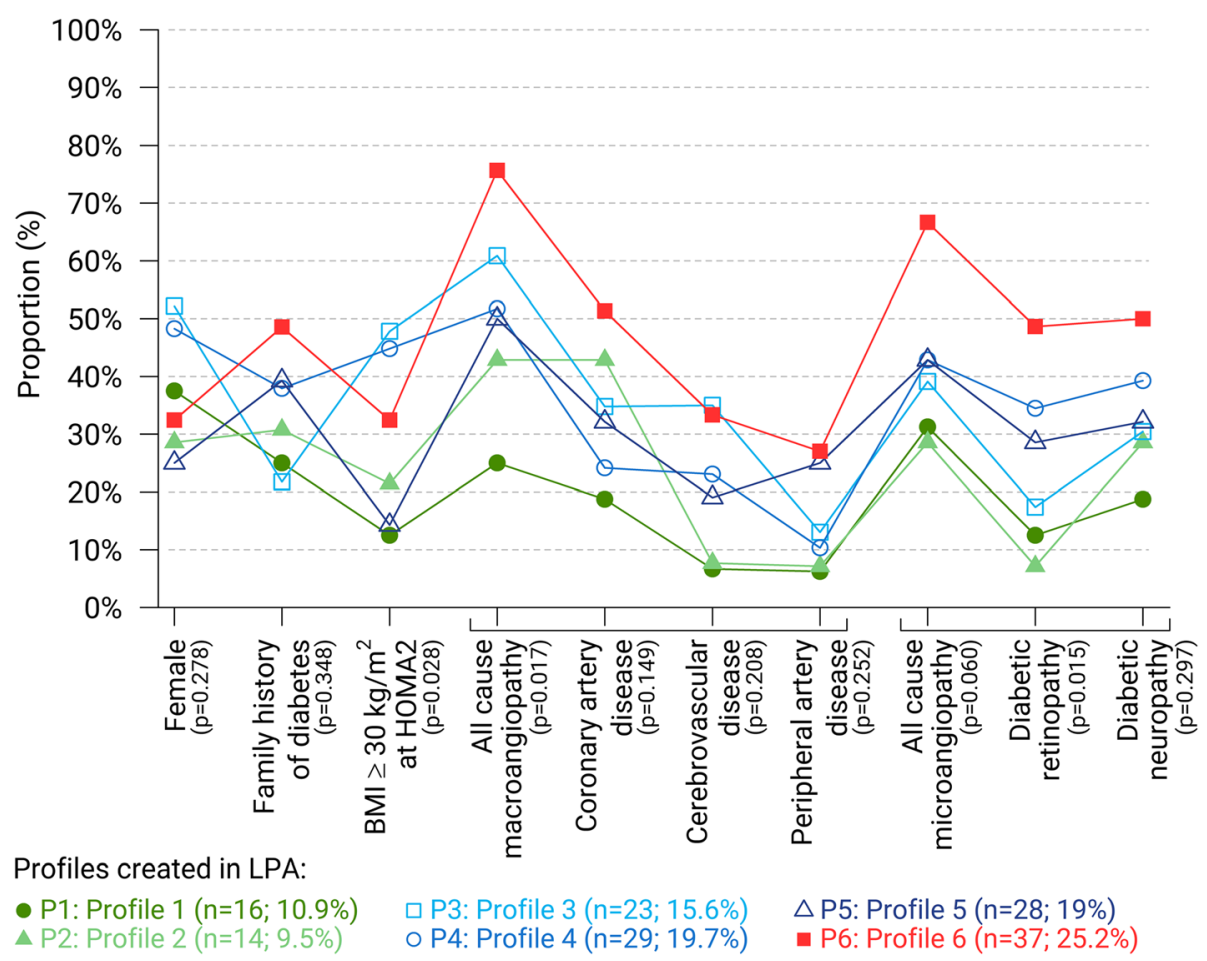

Fig. 3 Prevalence of women, family history of diabetes, BMI $\geq 30 \mathrm{~kg} / \mathrm{m}^{2}$, all cause macroangiopathy (coronary artery disease, cerebro-vascular disease and peripheral artery disease) and all cause microangiopathy (diabetic retinopathy and diabetic neuropathy) in each of the 6 profiles created by LPA. Statistical comparisons between profiles were performed using Pearson's $x^{2}$ test, Pearson's $x^{2}$ test with Yates correction or Fisher Freeman Halton's test according to the conditions of validity of each test

our model is to have HOMA2\%- $\beta \times S$ among input variables, bringing essential information on residual BCF to better identify patients whose needs and intensity of GLT escalation are more marked [19].

The use of these indicators allowed classifying patients into six distinct profiles. It highlights important phenotypic differences across patients sharing a common and seemingly unambiguous diagnosis of type 2 diabetes. Firstly, patients of profiles 1 and 2 had both the highest age at diabetes diagnosis combined with the highest $\beta x S$, whereas profile 6 patients had the youngest age at diabetes diagnosis and the lowest $\beta x S$. A link seems to exist between age at diabetes diagnosis and magnitude of glucose homeostasis' impairment, as shown in previous studies [24, 25]. This also implies that patients with an older age at diabetes diagnosis may need less intensive GLT, in terms of dose and drug of choice (e.g. use of hypoglycaemic agent). Inappropriate prescribing of hypoglycaemic agents in patients with late-onset type 2 diabetes may induce severe hypoglycaemic events.

Secondly, cardiometabolic risk, as shown by indices of insulin resistance, macrovascular comorbidities and BMI was very different between profiles. Some patients' profiles had lower BMI, lower insulin resistance and few macrovascular complications (e.g. profile 1), while other profiles had higher values of these variables (e.g. profile 6). Profiling older patients with type 2 diabetes thus confirms the rationale of bringing under control modifiable risk factors taking into account the cardiometabolic risk profile for the corresponding profile of individual patients.

The LPA method used allowed for distinguishing patients based on degree of insulin resistance and/or BCF loss. The quantification of these variables provides useful information to individualise GLT (e.g. hypoglycaemic agents when impaired $\mathrm{BCF}$ is the major driver of hyperglycaemia or biguanides when insulin resistance is in the foreground). This is all the more relevant given the absence of phenotypic overlap of different profiles of type 2 diabetes in older patients.

The strengths of the present study are twofold. First, all patients were followed by the same endocrinologist and data were prospectively collected by one dedicated clinician. This allows for standardization of all bioclinical measurements, increases as such data's quality and accuracy. Second, the HOMA2 was based on triplicates of fasting glucose and insulin levels sampled after a sufficient period of GLT washout. However, this sample of patients, most of whom Caucasians from a well-off Brussels suburb, 
Table 2 Patients' glucose-lowering therapy at the time of HOMA2 by pathophysiologic profiles $(N=147)$

\begin{tabular}{|c|c|c|c|c|c|c|c|}
\hline Variable & $\begin{array}{l}\text { Total }(N=147) \\
\text { Median [P25; } \\
\text { P75] } \\
\text { or } n(\%)\end{array}$ & $\begin{array}{l}\text { Profile } 1(n= \\
16) \\
\text { Median [P25; } \\
\text { P75] } \\
\text { or } n(\%)\end{array}$ & $\begin{array}{l}\text { Profile } 2(n= \\
\text { 14) } \\
\text { Median [P25; } \\
\text { P75] } \\
\text { or } n(\%)\end{array}$ & $\begin{array}{l}\text { Profile } 3(n= \\
23) \\
\text { Median [P25; } \\
\text { P75] } \\
\text { or } n(\%)\end{array}$ & $\begin{array}{l}\text { Profile } 4(n= \\
29) \\
\text { Median [P25; } \\
\text { P75] } \\
\text { or } n(\%)\end{array}$ & $\begin{array}{l}\text { Profile } 5(n= \\
28) \\
\text { Median [P25; } \\
\text { P75] } \\
\text { or } n(\%)\end{array}$ & $\begin{array}{l}\text { Profile } 6(n= \\
37) \\
\text { Median [P25, } \\
\text { P75] } \\
\text { or } n(\%)\end{array}$ \\
\hline Number of GLT drugs* & $\begin{array}{l}2.00[1.00 ; \\
2.00]\end{array}$ & $\begin{array}{l}1.00[1.00 ; \\
1.75]\end{array}$ & $\begin{array}{l}1.00[0.00 ; \\
2.00]\end{array}$ & $\begin{array}{l}1.00[0.00 ; \\
2.00]\end{array}$ & $\begin{array}{l}2.00[1.00 ; \\
2.00]\end{array}$ & $\begin{array}{l}1.00[1.00 ; \\
2.00]\end{array}$ & $\begin{array}{l}2.00[2.00 ; \\
2.00]\end{array}$ \\
\hline Lifestyle changes only & $21(14.3)$ & $3(18.8)$ & $4(28.6)$ & $7(30.4)$ & $1(3.4)$ & $6(21.4)$ & $0(0.0)$ \\
\hline Monotherapy & $52(35.4)$ & $9(56.3)$ & $5(35.7)$ & $8(34.8)$ & $12(41.4)$ & $11(39.3)$ & $7(18.9)$ \\
\hline Bitherapy & $61(41.5)$ & $3(18.8)$ & $5(35.7)$ & $6(26.1)$ & $13(44.8)$ & $11(39.3)$ & $23(62.2)$ \\
\hline Tritherapy & $13(8.8)$ & $1(6.3)$ & $0(0.0)$ & $2(8.7)$ & $3(10.3)$ & $0(0.0)$ & $7(18.9)$ \\
\hline GLT's total dose, in DDD & $\begin{array}{l}1.50[0.75 ; \\
2.28]\end{array}$ & $\begin{array}{l}0.75[0.35 ; \\
1.11]\end{array}$ & $\begin{array}{l}0.71[0.11 ; \\
1.33]\end{array}$ & $\begin{array}{l}0.85[0.00 ; \\
2.59]\end{array}$ & $\begin{array}{l}1.50[1.15 ; \\
2.10]\end{array}$ & $\begin{array}{l}1.14[0.41 ; \\
1.79]\end{array}$ & $\begin{array}{l}2.28[1.67 ; \\
2.85]\end{array}$ \\
\hline $\begin{array}{l}\text { GLT's total dose among users, } \\
\text { in DDD }\end{array}$ & $\begin{array}{l}1.67[0.89 ; \\
2.58]\end{array}$ & $\begin{array}{l}0.85[0.50 ; \\
1.43]\end{array}$ & $\begin{array}{l}0.79[0.69 ; \\
1.69]\end{array}$ & $\begin{array}{l}1.81[0.83 ; \\
2.86]\end{array}$ & $\begin{array}{l}1.53[1.21 \\
2.11]\end{array}$ & $\begin{array}{l}1.52[0.85 ; \\
2.07]\end{array}$ & $\begin{array}{l}2.28[1.67 ; \\
2.85]\end{array}$ \\
\hline \multicolumn{8}{|l|}{ GLT classes } \\
\hline \multicolumn{8}{|l|}{ Biguanides } \\
\hline Use & $79(53.7)$ & $8(50.0)$ & $5(35.7)$ & $9(39.1)$ & $18(62.1)$ & $16(57.1)$ & $23(62.2)$ \\
\hline DDD among users & $\begin{array}{l}0.85[0.57 ; \\
1.28]\end{array}$ & $\begin{array}{l}0.68[0.48 ; \\
0.85]\end{array}$ & $\begin{array}{l}0.50[0.43 ; \\
0.50]\end{array}$ & $\begin{array}{l}0.85[0.85 ; \\
1.28]\end{array}$ & $\begin{array}{l}0.85[0.50 ; \\
1.17]\end{array}$ & $\begin{array}{l}0.85[0.85 ; \\
1.28]\end{array}$ & $\begin{array}{l}0.85[0.80 ; \\
1.28]\end{array}$ \\
\hline \multicolumn{8}{|l|}{ Insulin } \\
\hline Use & $29(19.7)$ & $1(6.3)$ & $4(28.6)$ & $3(13.0)$ & $11(37.9)$ & $0(0.0)$ & $10(27.0)$ \\
\hline DDD among users & $\begin{array}{l}1.00[0.60 ; \\
1.35]\end{array}$ & 0.75 & $\begin{array}{l}0.34[0.31 ; \\
0.41]\end{array}$ & $\begin{array}{l}1.95[1.40 ; \\
2.16]\end{array}$ & $\begin{array}{l}1.05[0.73 ; \\
1.24]\end{array}$ & NA & $\begin{array}{l}1.28[0.93 ; \\
1.46]\end{array}$ \\
\hline \multicolumn{8}{|l|}{$\mathrm{OHA}$} \\
\hline Use & $79(53.7)$ & $8(50.0)$ & $5(35.7)$ & $10(43.5)$ & $15(51.7)$ & $12(42.9)$ & $29(78.4)$ \\
\hline DDD among users & $\begin{array}{l}1.50[1.00 ; \\
1.89]\end{array}$ & $\begin{array}{l}1.00[0.94 ; \\
1.00]\end{array}$ & $\begin{array}{l}1.43[1.00 ; \\
1.50]\end{array}$ & $\begin{array}{l}1.00[0.56 ; \\
2.04]\end{array}$ & $\begin{array}{l}1.50[0.88 ; \\
1.50]\end{array}$ & $\begin{array}{l}1.21[0.94 ; \\
1.57]\end{array}$ & $\begin{array}{l}1.50[1.43 ; \\
2.00]\end{array}$ \\
\hline \multicolumn{8}{|l|}{ Hypoglycemic agents } \\
\hline Use & $101(68.7)$ & $9(56.3)$ & $6(42.9)$ & $13(56.5)$ & $24(82.8)$ & $12(42.9)$ & $37(100.0)$ \\
\hline DDD among users & $\begin{array}{l}1.43[1.00 ; \\
1.79]\end{array}$ & $\begin{array}{l}1.00[0.75 ; \\
1.00]\end{array}$ & $\begin{array}{l}1.38[0.81 ; \\
1.77]\end{array}$ & $\begin{array}{l}1.00[0.75 ; \\
2.14]\end{array}$ & $\begin{array}{l}1.24[0.97 ; \\
1.50]\end{array}$ & $\begin{array}{l}1.21[0.94 ; \\
1.57]\end{array}$ & $\begin{array}{l}1.50[1.35 ; \\
2.00]\end{array}$ \\
\hline
\end{tabular}

GLT glucose-lowering therapy, DDD defined daily dose, OHA Oral hypoglycemic agents (=Sulfonylureas or Glinides); Hypoglycemic agents: Insulin and/or OHA. * Statistically significant difference between groups ( $p$-value $<0.001)$. NA not applicable

Table 3 Diabetes complications and comorbidities according to subgroups created from the latent profile analysis $(N=147)$

\begin{tabular}{|c|c|c|c|c|c|c|c|c|}
\hline Variable & $\begin{array}{l}\text { Total } \\
(N=147) \\
\mathrm{n}(\%)\end{array}$ & $\begin{array}{l}\text { Group } 1 \\
(n=16) \\
\mathrm{n}(\%)\end{array}$ & $\begin{array}{l}\text { Group } 2 \\
(n=14) \\
\mathrm{n}(\%)\end{array}$ & $\begin{array}{l}\text { Group } 3 \\
(n=23) \\
\mathrm{n}(\%)\end{array}$ & $\begin{array}{l}\text { Group } 4 \\
(n=29) \\
\mathrm{n}(\%)\end{array}$ & $\begin{array}{l}\text { Group } 5 \\
(n=28) \\
\mathrm{n}(\%)\end{array}$ & $\begin{array}{l}\text { Group } 6 \\
(n=37) \\
\mathrm{n}(\%)\end{array}$ & $P$-value \\
\hline Nephropathy & $97(66.0)$ & $13(81.3)$ & $7(50.0)$ & $15(65.2)$ & $20(69.0)$ & $17(60.7)$ & $25(67.6)$ & 0.584 \\
\hline Microangiopathy & $68(46.3)$ & $5(31.3)$ & $4(28.6)$ & $9(39.1)$ & $13(44.8)$ & $12(42.9)$ & $25(67.6)$ & 0.060 \\
\hline Diabetic retinopathy & $43(29.3)$ & $2(12.5)$ & $1(7.1)$ & $4(17.4)$ & $10(34.5)$ & $8(28.6)$ & $18(68.6)$ & 0.015 \\
\hline Diabetic neuropathy & $52(35.9)$ & $3(18.8)$ & $4(28.6)$ & $7(30.4)$ & $11(39.3)$ & $9(32.1)$ & $18(50.0)$ & 0.297 \\
\hline Macroangiopathy & $81(55.1)$ & $4(25.0)$ & $6(42.9)$ & $14(60.9)$ & $15(51.7)$ & $14(50.0)$ & $28(75.7)$ & 0.017 \\
\hline Coronary artery disease & $52(35.4)$ & $3(18.8)$ & $6(42.9)$ & $8(34.8)$ & $7(24.1)$ & $9(32.1)$ & $19(51.4)$ & 0.149 \\
\hline Cerebro-vascular disease & $28(23.0)$ & $1(6.7)$ & $1(7.7)$ & $7(35.0)$ & $6(23.1)$ & $4(19.0)$ & $9(33.3)$ & 0.208 \\
\hline Peripheral artery disease & $25(17.0)$ & $1(6.3)$ & $1(7.1)$ & $3(13.0)$ & $3(10.3)$ & $7(25.0)$ & $10(27.0)$ & 0.252 \\
\hline
\end{tabular}


was followed at a single-centre diabetes clinic, and may not de facto be representative of other populations of older patients with type 2 diabetes of various ethnicities.

Recently, Ahlqvist et al. provide a refined classification of diabetes using a data-driven cluster analysis [28], realised on a large cohort of Swedish patients with diabetes (ANDIS cohort, $N=8980$ ) and replicated on three independent cohorts $(N=5795)$. It classified patients into five clusters. Despite some similarities in the aims and variables chosen to classify patients, the study of Ahlqvist et al. differed from the present study in many ways.

First, the data used in ANDIS cohort were collected on incident cases at the time of the diabetes diagnosis (median time at inclusion $=40$ days after diagnosis) in adult patients aged from 18 to 96 years, with a mean age at diagnosis of 60.2 years. Our study included prevalent cases of patients diagnosed with type 2 diabetes $\geq 75$ years, with a median age at diagnosis of 62.0 years. Then, the inclusion criteria of Ahlqvist et al. were not restricted to type 2 diabetes but included all types of diabetes. The analytical method was a data-driven clustering, a classification method based on different theoretical approach as compared to latent profile analysis used in the present study. Finally, Ahlqvist et al. used six variables classifying patients into subgroups: three were identical to those used in the present study (HOMA2\%$\beta$, HOMA2\%-S and age at diabetes onset), while two were not used (body mass index (BMI), GAD-antibodies and $\mathrm{HbA1c}$ ). In the present study, BMI was not used, as it is not an optimal measure for obesity in older patients [29]. GAD-antibodies were not used, as the present study included only patients with type 2 diabetes. Regarding HbA1c, the present study used HOMA2\%- $\beta \mathrm{xS}$ instead, assessing the blood glucose control in patients taking glucose lowering therapies.

In the future, it might be of interest to assess the reproducibility of this study by increasing the number of patients, by recruiting older patients with diabetes followed by general practitioners and/or by running a study with a prospective design. It would allow predicting whether patients are ascribed to their appropriate profile and, accordingly, to propose therapeutic recommendations based on the patient's cardiometabolic profile, keeping in mind that such recommendations could only serve as complements to existing criteria for standards of care individualisation and current guidelines [8].

\section{Conclusions}

In conclusion, our study confirms the heterogeneity of cardiometabolic profiles in older type 2 diabetes patients, generating six profiles by LPA. The characterization of six distinct profiles could serve as decision-support indicators for choosing GLT, combined with existing criteria of therapeutic individualisation for older patients. Such classification could contribute to refine the current decision processes related to the control of hyperglycaemia, while limiting the risk of side effects such as hypoglycaemic episodes or therapeutic failure, aiming at a better overall management of the disease and its complications.

\section{Additional files}

Additional file 1: Latent profile analysis: Model fit statistics. Evaluative information (Goodness-of-fit statistics) for each k-profile model, including Log likelihood, Akaike Information Criterion (AIC), Bayesian Information Criterion (BIC) and Log Likelihood Ratio Test (LLRT). These statistics were used to select the best fitting number of profiles for the final latent profile anlaysis model. (DOCX $14 \mathrm{~kb}$ )

Additional file 2: Posterior probabilities associated with each profile in the six-profile model $(N=147)$. Posterior probabilities associated with each profile in the six-profile model $(N=147)$. (DOCX $16 \mathrm{~kb})$

\section{Abbreviations}

ATC: Anatomical Therapeutic Chemical (ATC) Classification System; BCF: Beta Cell Function; BMI: Body Mass Index; DDD: Defined Daily Dose; GLT: Glucose Lowering Therapy; HOMA2: Homeostasis Model Assessment 2; LADA: Latent Autoimmune Diabetes in Adults; LPA: Latent Profile Analysis; OHA: Oral Hypoglycaemic Agents

\section{Acknowledgments \\ The authors would like to thank all study participants.}

\section{Authors' contributions}

MPH followed all patients and collected all data. AC abstracted the data. AC and $\mathrm{SH}$ performed the analyses and interpreted the data. AC wrote the draft of the manuscript, and $\mathrm{SH}, \mathrm{BB}$ and $\mathrm{MPH}$ reviewed the manuscript. All authors have read and approved the final manuscript.

\section{Funding}

This study was supported by a Research Fellow grant (A.C.) from the Fund for Scientific Research - FNRS (Belgium). The funding body (Fund for Scientific Research - FNRS) played no part in the design of the study and collection, analysis, interpretation of data or in writing the manuscript.

\section{Availability of data and materials}

The datasets generated and/or analysed during the current study are not publicly available due to restrictions on patients' anonymity but are available from the corresponding author on reasonable request.

\section{Ethics approval and consent to participate}

This study was approved by the Institutional Review Board (Commission d'Ethique Hospitalo-Facultaire, Cliniques universitaires Saint-Luc, Brussels, Belgium; IRB 00001530 - IRB 00008535; Approval ref. B 403 / 2017/16NOV/ 521). According to the national regulations and approval of the Institutional Review Board (Commission d'Ethique Hospitalo-Facultaire, Cliniques universitaires Saint-Luc, Brussels, Belgium), there was no need for informed consent to participate in this retrospective study, as long as the investigators have verified the refusal of use of the retrospective data for scientific research issued by the patients.

\section{Consent for publication}

Not applicable.

\section{Competing interests}

The authors declare that they have no competing interests.

\section{Author details}

${ }^{1}$ Fonds national de la recherche scientifique - F.R.S-FNRS, Brussels, Belgium ${ }^{2}$ Clinical Pharmacy Research Group, Louvain Drug Research Institute (LDRI), UCLouvain, Brussels, Belgium. ${ }^{3}$ Institute of Health and Society (IRSS), 
UCLouvain, Brussels, Belgium. ${ }^{4}$ Institute of Experimental and Clinical Research, UCLouvain, Brussels, Belgium. ${ }^{5}$ Endocrinology unit, Saint-Luc University Hospital, Brussels, Belgium. ${ }^{6}$ Geriatric medicine unit, Saint-Luc University Hospital, Brussels, Belgium.

\section{Received: 8 March 2019 Accepted: 17 July 2019}

Published online: 05 August 2019

\section{References}

1. International Diabetes Federation. IDF diabetes atlas 2017.

2. Zhang P, Zhang X, Brown J, Vistisen D, Sicree R, Shaw J, et al. Global healthcare expenditure on diabetes for 2010 and 2030. Diabetes Res Clin Pract. 2010;87(3):293-301.

3. American Diabetes Association. 2. Classification and diagnosis of diabetes: standards of medical Care in Diabetes-2018. Diabetes Care. 2018;41(Suppl 1): S13-27.

4. Dhaliwal R, Weinstock RS. Management of Type 1 diabetes in older adults. Diabetes Spectr. 2014;27(1):9-20.

5. Stenstrom G, Gottsater A, Bakhtadze E, Berger B, Sundkvist G. Latent autoimmune diabetes in adults: definition, prevalence, beta-cell function, and treatment. Diabetes. 2005;54(Suppl 2):S68-72.

6. Espinoza SE, Jung I, Hazuda H. Frailty transitions in the San Antonio longitudinal study of aging. J Am Geriatr Soc. 2012;60(4):652-60.

7. Clegg A, Young J, lliffe S, Rikkert MO, Rockwood K. Frailty in elderly people. Lancet. 2013;381(9868):752-62.

8. American Diabetes Association. 11. Older adults: standards of medical Care in Diabetes-2018. Diabetes Care. 2018;41(Suppl 1):S119-S25.

9. Dunning T, Sinclair A, Colagiuri S. New IDF guideline for managing type 2 diabetes in older people. Diabetes Res Clin Pract. 2014;103(3):538-40.

10. Inzucchi SE, Bergenstal RM, Buse JB, Diamant M, Ferrannini E, Nauck M, et al. Management of hyperglycemia in type 2 diabetes: a patient-centered approach: position statement of the American Diabetes Association (ADA) and the European Association for the Study of diabetes (EASD). Diabetes Care. 2012;35(6):1364-79.

11. Kirkman MS, Briscoe VJ, Clark N, Florez H, Haas LB, Halter JB, et al. Diabetes in older adults. Diabetes Care. 2012;35(12):2650-64

12. Raz I, Riddle MC, Rosenstock J, Buse JB, Inzucchi SE, Home PD, et al. Personalized management of hyperglycemia in type 2 diabetes: reflections from a diabetes care Editors' expert forum. Diabetes Care. 2013;36(6):1779-88.

13. McLaren LA, Quinn TJ, McKay GA. Diabetes control in older people. BMJ. 2013;346:f2625.

14. Del Prato S, LaSalle J, Matthaei S, Bailey CJ. Global Partnership for Effective Diabetes $M$. tailoring treatment to the individual in type 2 diabetes practical guidance from the global Partnership for Effective Diabetes Management Int J Clin Pract. 2010;64(3):295-304

15. Sinclair A, Morley JE, Rodriguez-Manas L, Paolisso G, Bayer T, Zeyfang A, et al. Diabetes mellitus in older people: position statement on behalf of the International Association of Gerontology and Geriatrics (IAGG), the European diabetes working Party for Older People (EDWPOP), and the international task force of experts in diabetes. J Am Med Dir Assoc. 2012;13(6):497-502.

16. de Rekeneire N, Peila R, Ding J, Colbert LH, Visser M, Shorr Rl, et al. Diabetes, hyperglycemia, and inflammation in older individuals: the health, aging and body composition study. Diabetes Care. 2006:29(8):1902-8.

17. Lee $P G$, Halter JB. The pathophysiology of hyperglycemia in older adults: clinical considerations. Diabetes Care. 2017:40(4):444-52.

18. Scheen AJ. Diabetes mellitus in the elderly: insulin resistance and/or impaired insulin secretion? Diabetes Metab. 2005;31 Spec No 2:5S27-5S34.

19. Kahn SE, Prigeon RL, McCulloch DK, Boyko EJ, Bergman RN, Schwartz MW et al. Quantification of the relationship between insulin sensitivity and betacell function in human subjects. Evidence for a hyperbolic function. Diabetes. 1993;42(11):1663-72.

20. Levy JC, Matthews DR, Hermans MP. Correct homeostasis model assessment (HOMA) evaluation uses the computer program. Diabetes Care. 1998;21(12): 2191-2

21. Methodology. WCCFDS. Guidelines for ATC classification and DDD assignment 2018. Oslo. 2017

22. UK Prospective Diabetes Study group (UKPDS). UK Prospective Diabetes Study (UKPDS). VIII. Study design, progress and performance. Diabetologia 1991;34(12):877-890
23. Nylund $K$, Asparouhov T, Muthén B. Deciding on the number of classes in latent class analysis and growth mixture modeling: a Monte Carlo stimulation study. Struct Equ Model. 2007;14(4):15.

24. Wang Y, Qin MZ, Liu Q, Liu Q, Chang ZW. Clinical analysis of elderly patients with elderly-onset type 2 diabetes mellitus in China: assessment of appropriate therapy. J Int Med Res. 2010;38(3):1134-41.

25. Bentata $Y$, Intissar H, Ilham K, Nawal B, Abdeljalil C, Abouqal R. Diabetes onset before or after the age of 65-does it affect the progression of renal and cardiovascular diseases in the elderly patient? J Geriatr Cardiol. 2016;13(3):267-9.

26. Lee BK, Kim SW, Choi D, Cho EH. Comparison of age of onset and frequency of diabetic complications in the very elderly patients with type 2 diabetes. Endocrinol Metab (Seoul). 2016;31(3):416-23.

27. Zhang S, Wang J, Song C, Zhu L, Yu Y. Lower prevalence of proliferative diabetic retinopathy in elderly onset patients with diabetes. Diabetes Res Clin Pract. 2017;125:47-52

28. Ahlqvist $E$, Storm $P$, Käräjämäki $A$, Martinell $M$, Dorkhan $M$, Carlsson $A$, et al. Novel subgroups of adult-onset diabetes and their association with outcomes: a data-driven cluster analysis of six variables. Lancet Diabetes Endocrinol. 2018;6(5):361-9.

29. Gill LE, Bartels SJ, Batsis JA. Weight Management in Older Adults. Curr Obes Rep. 2015:4(3):379-88.

\section{Publisher's Note}

Springer Nature remains neutral with regard to jurisdictional claims in published maps and institutional affiliations.
Ready to submit your research? Choose BMC and benefit from:

- fast, convenient online submission

- thorough peer review by experienced researchers in your field

- rapid publication on acceptance

- support for research data, including large and complex data types

- gold Open Access which fosters wider collaboration and increased citations

- maximum visibility for your research: over $100 \mathrm{M}$ website views per year

At $\mathrm{BMC}$, research is always in progress.

Learn more biomedcentral.com/submissions 